\title{
Rebuilding and restructuring the world following rapid comprehensive assessment and treatment for an acute stroke
}

\author{
Joanne Mary Brooke * \\ Department of Nursing and Quality, Kent Community Health NHS Trust, United Kingdom
}

$\begin{array}{ll}\text { Received: January 9, } 2015 & \text { Accepted: February 26, 2015 } \quad \text { Online Published: March 10, } 2015 \\ \text { DOI: } 10.5430 / \text { cns.v3n3p1 } & \text { URL: http://dx.doi.org/10.5430/cns.v3n3p1 }\end{array}$

\begin{abstract}
Management of acute stroke has changed through implementation of rapid comprehensive assessment and treatment. Stroke as a medical emergency and expectancy of recovery has implications on how patients cognitively process the impact of their stroke. Current literature focuses on long term recovery and little is known about patients' experiences and cognitive processing during the acute phase. Semi-structured interviews were completed with 6 patients on a stroke unit, London, UK, between October and December 2012. The interview schedule was based on interviews with a clinical nurse specialist, stroke patient and previous literature. Interviews took place during hospital admission following transfer from a hyper acute stroke unit. Data were analysed using Interpretative Phenomenological Analysis. Participants ages ranged from 68 to 94 years, the emergent super-ordinate themes from this sample receiving a diagnosis of an acute stroke included: (1) disassociation from bodies, self and abilities; (2) search for understanding; (3) striving for independence and acceptance of support; and (4) hope and uncertainty. Although there were variations in participants' experiences these themes capture the experience of the participants collectively. All participants applied cognitive processes to commence the rebuilding and restructuring of their world. Participants began this process in the acute stage of their stroke.
\end{abstract}

Key Words: Acute stroke, Qualitative, Interpretative phenomenological analysis, Patients' perspective

\section{INTRODUCTION}

The burden of stroke in developed countries has changed, but continues in the 21st Century. The incidence of stroke has decreased through primary prevention, but the prevalence of stroke is increasing due to an aging population. ${ }^{[1,2]}$ The burden of stroke has been addressed by rapid comprehensive assessment and treatment, which has changed stroke care and management over the last decade. ${ }^{[3]}$ Implementation of thrombolysis as a treatment of ischemic stroke when administered within three hours of onset has improved stroke outcomes. ${ }^{[4]}$ Thrombolysis was first administered in the US in 1996, Canada in 1999 and Europe, including the UK in 2002. ${ }^{[5]}$ In the UK, provision of stroke specialist units alongside comprehensive access to thrombolysis has reduced mortality, patients' hospital length of stay and the likelihood of being discharged home rather than to institutionalised care. ${ }^{[6,7]}$

Stroke impacts on every aspect of an individual's life including physical, cognitive and emotional functioning. ${ }^{[8]}$ Associations between neurological deficits and quality of life

\footnotetext{
* Correspondence: Joanne Mary Brooke; Email: joanne.brooke@kentcht.nhs.uk; Address: Department of Nursing and Quality, Kent Community Health NHS Trust, United Kingdom.
} 
are not stable ${ }^{[9]}$ or synonymous. ${ }^{[10]}$ Recovery from stroke involves rebuilding and restructuring of the patient's world beyond neurological deficits in a social context. ${ }^{[11]}$

Studies completed prior to implementation of thrombolysis, such as Nilsson, et al., found acute phases of stroke were characterised by overwhelming physical, psychological and social losses and patients struggled to find meaning in life and needed to address the concept of "being". ${ }^{[12]}$ Post thrombolysis implementation, a four stage model, has been proposed to capture the recovery process. ${ }^{[13,14]}$ During the acute stages of stroke, patients are not overwhelmed by losses but adopt both optimism and expectations of returning to health as well as a "wait and see" approach due to the un-predictableness of their recovery. Following discharge from hospital patients begin to experience their body in a more negative manner, as lethargy impacts on their ability to complete tasks efficiently. Patients then begin to focus on self-understanding and getting on with life. ${ }^{[13,14]}$

Patients cognitive processing of the impact of their stroke in the hyper acute phase is an important element for healthcare professionals to incorporate in care planning. Further phenomenological studies are required to understand the cognitive and emotional strategies of patients apply when beginning the process of rebuilding and restructuring their world following a stroke. An understanding of patients' strategies would inform the development of care, pathways and services.

\section{Aim}

To further understand cognitive processes of rebuilding and restructuring of an individual's world following hyper acute assessment and treatment for stroke.

\section{MeTHODS}

\subsection{Design}

The design of the study was informed by Interpretative Phenomenological Analysis (IPA) including the three components of phenomenology (the study of experience), hermeneutics (the theory of interpretation) and idiographic (a particular person making sense of their experience). ${ }^{[15]}$ The study was phenomenological to allow an exploration of how participant's made sense of their experience of having a stroke and the impact on their "being" in the world. Being in the world draws on Heidegger's phenomenology of "Dasein", this is interpreted as "there being" or "being there". Individuals are always somewhere, always located and always among and involved with some kind of meaningful context. ${ }^{[17]}$

\subsection{Participants}

Participants were recruited from a stroke unit in London, UK. The inclusion criteria were: a primary diagnosis of a first ever stroke, aged over 18 years and the ability to communicate in English. The exclusion criteria were: diagnosis of cognitive impairment, severe receptive and/or expressive dysphasia or severe dysarthria. A total of three men and three women were recruited; age ranged from 68 to 94 years, four were White British, one Black British and one White American. All participants lived independently prior to their stroke. Interviews were conducted between 5 to 10 days post stroke and lasted between 11 to 34 minutes (see Table 1).

Table 1. Participants demographic data (to maintain anonymity of participants all names are synonyms)

\begin{tabular}{|c|c|c|c|c|c|}
\hline & Gender & Ethnicity & Age & Independence pior to stroke & Length of time since stroke (days) \\
\hline Anne & Female & White British & 94 & Independent living alone & 6 \\
\hline Bert & Male & White British & 68 & Independent living alone & 10 \\
\hline Carol & Female & Black British & 76 & Independent living alone & 8 \\
\hline David & Male & White American & 83 & Independent living with wife & 6 \\
\hline Edna & Female & White British & 72 & $\begin{array}{l}\text { Independent living alone, daily } \\
\text { visits from community nurse team }\end{array}$ & 9 \\
\hline Fred & Male & White British & 79 & Independent living alone & 5 \\
\hline
\end{tabular}

\subsection{Data collection}

Data were collected via semi-structured interviews. An interview schedule was developed from published phenomenological research within stroke and intensive care settings. ${ }^{[18-20]}$ The interview schedule was then pilot tested with a clinical nurse specialist and a patient currently in hospital following a stroke. Following the pilot test one question was altered from "What impact do you think your stroke will have on your future?" to "What impact do you think your stroke will have when you go home?" The stroke patient highlighted whilst in hospital the main focus was on returning home rather than thinking beyond this goal (see Table 2). The interview schedule contained open-ended questions to allow participants to explore their experiences of an acute stroke. 
All interviews were participant led to allow the participant to guide the interview and the researcher to follow-up interesting possibilities emerging during the interview. ${ }^{[21]}$ However, the question schedule was revisited to ensure all relevant topics had been covered. All interviews were completed by the same researcher.

\subsection{Ethics}

Ethical approval was obtained from the NRES Committee London and Site Specific Assessment was completed and approved by the Research and Development for the NHS Trust where recruitment occurred. All participants were provided with participant information sheets and allowed time to discuss the study with friends and family, and staff members prior to providing informed consent.

Table 2. The interview schedule

\begin{tabular}{ll}
\hline No. & Questions \\
\hline 1 & Can you explain what happened to bring you into hospital? \\
2 & How did the stroke affect you? \\
3 & How has the stroke affected your mood? \\
4 & Can you explain your transfer to this unit? \\
6 & How are you coping with the effects of your stroke? \\
\hline
\end{tabular}

\subsection{Data analysis}

Interviews were audio recorded and transcribed verbatim. Data was analysed by applying the six stages of IPA; these form a set of common processes and principles which can be applied flexibly according to the requirements of individual studies. ${ }^{[22]}$ Analysis commenced by the first author reading and re-reading the transcript from the first interview to become familiar with the data. The next stage involved initial noting on the transcript of points of interest. Themes were then constructed from the points of interest and with constant referral back to the original text. On completion of the development of themes, connections across themes were searched for. This process was completed for each individual transcript prior to the search for patterns across all transcripts. No theoretical concepts were applied during data analysis; themes emerged solely from analysis of the data.

\subsection{Rigor}

The phenomenological interpretative approach allowed a particular lived experience to be studied in depth with a clear and structured method. ${ }^{[15]}$ Implementation of the Heideggerian approach to phenomenological research ${ }^{[23]}$ allowed bracketing of pre-conceptions as they arose, to avoid researcher bias. Audio recording, verbatim transcriptions and initial noting aided the reliability and transparency of data analysis. Emergent themes were discussed with the researchers' supervisor to achieve further transparency and triangulation of data. Themes reported are one possible account of participants' cognitive and emotional responses to rebuilding and restructuring their world following a stroke. Themes do not cover all aspects of the patients' experience and were selected due to their relevance to the aims of the research.

\section{RESULTS}

Four themes emerged from the data: (1) Disassociation from bodies, self and abilities. (2) Search for understanding. (3) Striving for independence and acceptance of support. (4) Hope and uncertainty. Figure 1 illustrates the subthemes involved in the development of the above themes.

\subsection{Disassociation from bodies, self and abilities}

Participants expressed disassociation from bodies, self and abilities through their descriptions of the impact of their stroke. Disassociation allowed the participants to temporarily separate themselves from their current situation and was applied when describing the immediate and severe impact of their stroke. However, participants changed the way they described their bodies, self and abilities when discussing their recovery.

Carol disassociated herself from her affected foot by using the definite article "the foot" rather than the possessive article of "my foot": I had no life in my body, none at all ... it went dead, all of my body went dead ... but umm ... the foot is the main thing now. The rest of my body came back, but the foot is the main problem. Later Carol's disassociation with her foot changes as she discusses her recovery: It (her foot) is coming back gradually, my foot is better because a couple of days ago I couldn't walk without help from the nurses, and now I can walk.

Edna disassociated herself from her current situation by describing her past and present independence interchangeably: 
Before this (stroke) I was independent. I lived on my own, I have multiple sclerosis but that hasn't stopped me living at home on my own. I like to be independent... I remain independent. I like to do things for myself, I like to be independent. However, Edna later acknowledges the unlikelihood of remaining independent: My left side is useless ... There is talk of me going to a nursing home, because of the amount of care I need. I don't mind going ... if I get the care and attention I need I don't mind going.

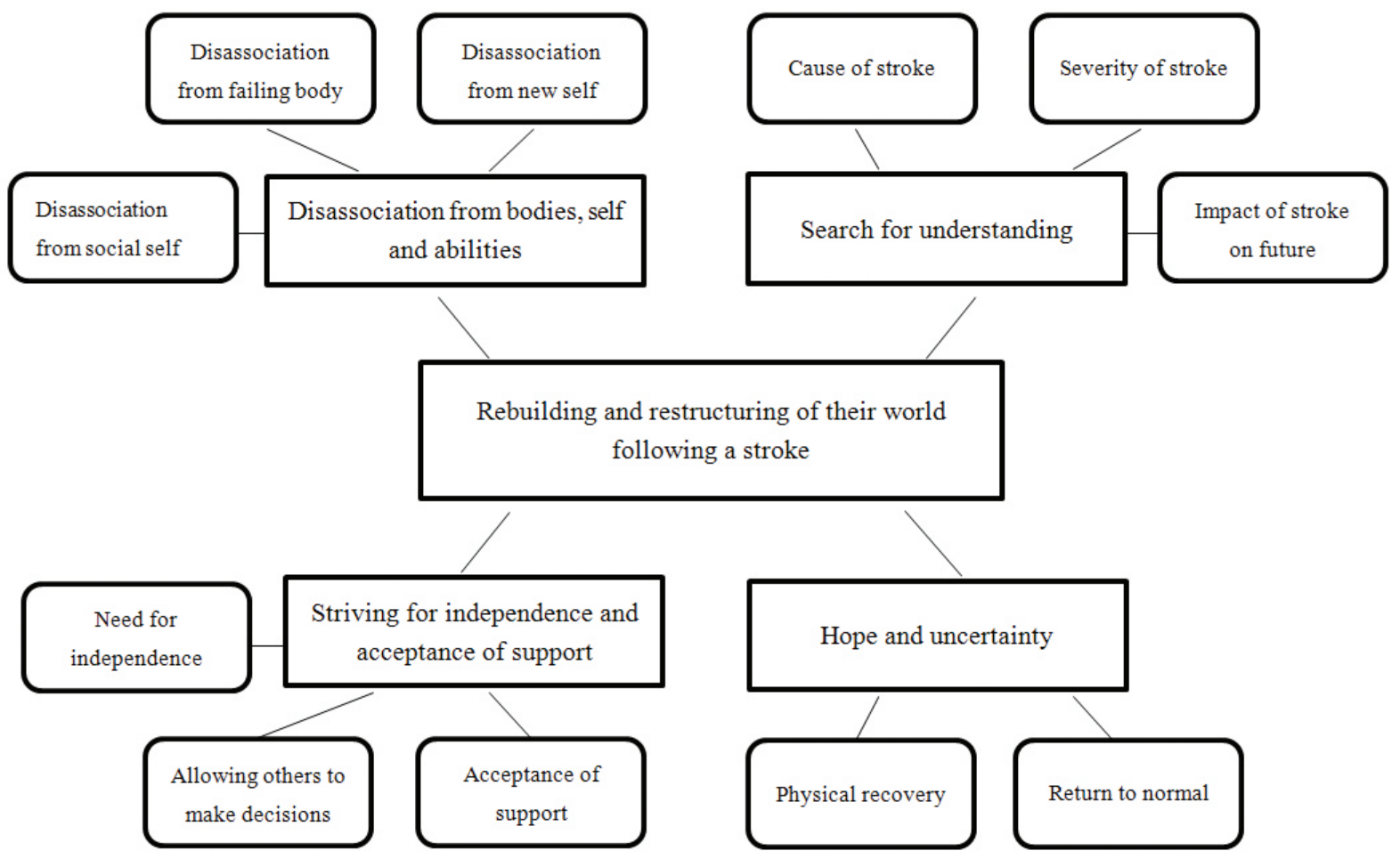

Figure 1. Thematic map showing themes and sub-themes

\subsection{Search for understanding}

Participants searched for understanding by exploring the reasons why their stroke had occurred and the impact of their stroke on their future lives. Participants were working through assessments of their health to identify predictive factors for their stroke. The impact of the stroke was assessed by participants through social comparisons of patients with more or less focal deficits.

Fred's search for understanding had identified episodes of ill health that might have been a warning that he was at risk of a stroke. Three weeks prior to that (his stroke) at home I had two nights on two occasions when I couldn't sit upright at 3 am ... I called an ambulance and they checked me over and the report said everything was perfectly alright ... but had I followed up the complaint and had a head scan it might have saved me from having this stroke....

Bert completed a downward social comparison, which allowed him to minimise the severity of his stroke and to conclude he had not been adversely affected: Apparently I had a light stroke, which was one good thing because the people around me are really out of it ... he (describing a fellow patient) shouts and screams, then he cries. He wanders all over the place; honestly he can't help it.

David, who had severe weakness of his arm and leg completed an upward social comparison by discussing an acquaintance who at the same age was in poor health prior to his stroke: I have seen people with a stroke ... a person with two new knees a heart bypass and he had a stroke, he was 83 year old chap but two weeks later was back walking.

\subsection{Striving for independence and acceptance of sup- port}

Participants expressed striving for independence and acceptance of support through declarations of a need to remain independent but simultaneously accepting the support from healthcare professionals, family and friends. Participants were striving for independence with reliance on their own capabilities, judgements and resources, however participants acknowledged the support of others to enable this process.

David expressed how he strived for independence through 
hard work and physiotherapy: When I stand up I get wobbly because my knee is weak and can give way. I need to practice standing still, to stand strong. I need to keep practicing to stand strong and strengthen my knee.

Anne expressed her need for independence to avoid her greatest fear of being admitted to a nursing home: I shall stagger on a bit. I'm trying, I need to, my one fear and it is a fear I have always been frightened of going into a home. I would fight that to the nail if I could you know....

Anne simultaneously expressed her reliance on others to make decisions for her and the need to accept some help when discharged home: My cousin has made arrangements for social services to come... The nurse said she is going to get on to social services... I must admit to be perfectly honest I would rather they didn't (social services visit), but that is just one of those things and when you are in the situation that I'm going to be in for a while at least one has to do is knuckle under a bit.

\subsection{Hope and uncertainty}

Participants associated hope with complete recovery from their stroke and associated uncertainty with the extent to which their recovery would enable them to return to their past lives.

Carol expressed hope and uncertainty regarding returning to normal through hard work and physiotherapy: I'm getting better all the time doing physiotherapy, I have been there today, it is good for me to do you know, hard work. I will recover and hope to come back to my normal self.

Bert expressed hope regarding returning to his hobbies: I hope to go back to watch home games (Premier League football) again when I leave here and go to the café. I have a café what I use ... it's like a working men's club, they care, you see all the regulars... I hope to go back and chat with all my mates.

Bert expressed uncertainty regarding how he would cope at home: I'm going back to live on my own, I don't really know how I will cope, because at the moment I'm stuck in bed or by the bed, one of the two. I will have to wait until I get home and then see what it is like.

\section{Discussion}

In the acute phase of stroke participants were in the process of completing cognitive tasks to understand their sudden and dramatic change due to the impact of their stroke, which involved several collective cognitive processes.

\subsection{Disassociation from bodies, self and abilities}

Disassociation from bodies, self and abilities is consistent with the first stage of Eilertsen, et al.'s recovery model, which focuses on the impact of bodily changes on participants' concepts of their body and self during the acute phase. ${ }^{[14]}$ A model of restoring embodied control, constructed from experiences of patients recovering from colorectal surgery, defines 4 stages. ${ }^{[24]}$ Stage 1 defines disembodiment, which occurred in the current study through disassociation from bodies, self and abilities. Stage 2 included re-familiarisation of participants with their bodies that now functioned differently. Stage 3 allowed participants to reclaim control through physical improvements. Stage 4 included participants return to embodied control.

The restoring embodied control model ${ }^{[24]}$ is relevant to patients following a stroke, although does not allow for continued deficits, which may be permanent following a stroke leading to continued disembodiment. Murray and Harrison identified disrupted disembodiment and loss of self in participants two years following their stroke. ${ }^{[25]}$ Therefore, a tentative model would include Eilertsen, et al.'s recovery mode ${ }^{[14]}$ and the 4 stage model of restoring embodied control ${ }^{[24]}$ in or across both acute and chronic phases of recovery from a stroke.

\subsection{Search for understanding}

Participants applied causal attributions ${ }^{[16,26]}$ to understand the cause of their stroke. Causal attributions can impact on; poorer emotional adjustment and quality of life, ${ }^{[27]}$ poorer health outcomes ${ }^{[28]}$ and patients' future health decisions. ${ }^{[29]}$ Therefore it is important to understand patients' cognitive understanding of their stroke and the attribution of external or internal factors that they may or may not have control over. Healthcare professionals could inform the process of applying causal attributions that patients do have control over, which may impact positively on long-term outcomes.

Participants searched to understand the severity of their stroke by comparing themselves with other patients and friends with a diagnosis of stroke. Individuals have a basic need to maintain a stable and accurate view of themselves. ${ }^{[30]}$ Downward comparisons enable individuals to compare themselves with someone less fortunate ${ }^{[31]}$ and adjust to their illness. ${ }^{[32]}$ Downward comparisons were made by participants to minimise the impact of their stroke.

Upward comparisons fulfil the need to self-improve and can motivate people by providing information on how to make progress. ${ }^{[33]}$ The upward comparison of the participant in the current study was to provide a role model to demonstrate the possibility of improved physical functioning and provided 
hope. ${ }^{[34]}$

The use of social comparisons by patients adapting to a chronic illness was studied by Arigo, et al., with positive upward comparisons associated with better coping skills and positive downward comparison with more severe illnesses. ${ }^{[35]}$ The current study identified both upward positive and downward positive social comparisons in participants following stroke. However the impact of these cognitive tasks in the acute stage of stroke on the rehabilitation process is unknown.

\subsection{Striving for independence and acceptance of sup- port}

The participants in the current study expressed the need to return to independent living, whilst none of the participants were actively involved or expressed the need to be involved in planning their discharge. Participants lack of involvement in the decision making process is an important finding as an emphasis and belief in patient involvement is longstanding. ${ }^{[36]}$

Thompson identified three domains in a dynamic model which influence the level of patient involvement in healthcare decisions. ${ }^{[37]}$ Firstly, the need for healthcare: patients involvement was less if illness was acute and serious compared to chronic with less serious consequences. Secondly, personal characteristics: level of involvement depended on patients knowledge and personal traits. Thirdly, professional relationships: patients involvement increased as levels of trust for healthcare professionals decreased. Participants in the current study were recovering from an acute illness and expressed confidence in healthcare professionals, supporting Thompson's model. ${ }^{[37]}$ However, participants with less serious implications of their stroke were less likely to be involved in healthcare decisions. The inconsistency maybe stroke specific, as stroke is an acute illness with severe consequences and a chronic illness with long-term implications. The importance of patient involvement within stroke services needs to be explored further to understand the impact of stroke as a chronic illness with long term complications following an acute phase.

\subsection{Hope and uncertainty}

Hope and uncertainty were simultaneously expressed by participants regarding their recovery. This is comparable to Eilersten, et al. stage of optimism of returning to health but simultaneously expressing a wait and see approach to recovery. ${ }^{[14]}$ Hope has been identified as an important part of the process of recovery from illness. ${ }^{[38]}$ The influence of hope during rehabilitation on long term recovery is acknowledged. ${ }^{[39]}$ However, the emergence of hope within the first 10 days following a stroke is unique and the impact on long-term recovery is yet unknown.

There are multiple definitions of hope following stroke. ${ }^{[18,40]}$ Bright, et al., defined hope as an inner strength, being positive in nature and included patients' wishes to return to a normal way of life, normal roles, and normal activities. ${ }^{[20]}$ This is comparable with participants in the current study as they discussed reliance on their own inner strengths to return to their lives prior to the stroke. This element of hope is comparable to resilience, which enhances both physical health and quality of life in older adults. ${ }^{[41,42]}$ However, the concept of resilience within stroke has had little attention. Glymour, et al., found cognitive resilience post stroke was promoted by social interaction. Participants in the current study expressed the importance of family and social support. ${ }^{[43]}$

The model of hope after stroke ${ }^{[20]}$ is an important working definition of hope, which will allow patients with less hope in the acute phase to be identified and provided with appropriate support from healthcare professionals.

\subsection{Limitations}

The study limitations include the recruitment of participants from one stroke unit in London. Recruitment for the study was systematic, although excluded participants with speech and language difficulties and cognitive impairment post stroke. Screening of 30 potential participants occurred with seven identified as fulfilling the study criteria, one of which declined to participate. All participants were aged over 68 years and therefore the findings of this study are only relevant to the older population of people with a diagnosis of stroke.

\section{CONClusion AND RELEVANCE TO Clini- CAL PRACTICE}

Future work regarding patients' cognitive processes in the acute stage following a stroke is imperative. The impact of cognitive processing such as disembodiment, causal attributions and hope has clear implications for long-term rehabilitation outcomes. Stroke is a condition where patients need to take an active lead in their recovery process, identifying cognitive processes that may inhibit this is essential. The implementation of routine assessment of cognitive processes and an intervention to provide support to enable positive processing needs to be developed.

Assessments of cognitive processes will be a new approach for many members of the multi-disciplinary stroke team as the current focus is on physical, social and mood assessment. Nurses could explore patient's causal attributions in their routine battery of assessments via a validated questionnaire 
such as the Internal, Personal and Situational Attributions Questionnaire (IPSAQ). ${ }^{[4]}$ A different approach could be an informal discussion led by a nurse to understand the patient's current cognitive processing of their stroke to enable the multi-disciplinary team to tailor interventions appropriately. However, all members of the multi-disciplinary team need to be aware of a patient's cognitive processing especially when explaining the cause of the stroke, treatment and the need for intense physiotherapy. Multi-disciplinary stroke teams will require training and support from psychologists to ensure the assessment of cognitive processes is completed within a robust, safe and validated approach.

\section{REFERENCES}

[1] Rothwell PM, Coull AJ, Silver LE, et al. Population-based study of event-rate, incidence, case fatality, and mortality for all acute vascular events in all arterial territories (Oxford Vascular Study). Lancet. 2005; 366(9466): 1773-1783. http://dx.doi.org/10.1016/S 0140-6736 (05) 67702-1

[2] Mukherjee D, Patil C. Epidemiology and the global burden of stroke. World Neurosurg. 2011; 76(6): S585-590.

[3] Dermain V, Zikic M, Zikic R. Stroke: a historical overview and contemporary management. Current Topics in Neurology, Psychiatry and Related Disciplines. 2011; 19(2): 15-23.

[4] Wardlow JM, Sandercock PAG, Berge E. Thrombolytic therapy with recombinant tissue plasminogen activator for acute ischemic stroke. Where do we go from here? A cumulative meta-analysis. Stroke. 2003; 34: 1437-1442. PMID::12730560. http://dx.doi.org/10. 1161/01. STR.0000072513.72262.7E

[5] Wahlgren N, Ahmed N, Davolos A, et al. Thrombolysis with alteplase for acute ischemic stroke in the Safe Implementation of Thrombolysis in Stroke-Monitoring Study (SITS-MOST): an observational study. Lancet. 2007; 369: 275-282. http://dx.doi .org/10.1016/S01 40-6736 (07) 60149-4

[6] Brooke J, Kar A, Ames D. Impact of hyper acute stroke unit on length of hospital stay and discharge destination; Imperial College Healthcare NHS Trust. Int J Stroke. 2010; suppl 3: 30.

[7] Cohen DL, Bathula R, Fenwich-Elliot S, et al. Thrombolysis rates, repatriation and 30-day outcome from a new comprehensive stroke service in a London district teaching hospital. Int J Stroke. 2010; 5(suppl 3): 31

[8] National Stroke Association. Cognitive problems post stroke. 2013. Available from: http://www.stroke.org.uk/about/cognitiv e-problems

[9] Suenkeler IH, Nowak M, Misselwitz B, et al. Time course of healthrelated quality of life as determined by 3, 6 and 12 months after stroke. Relationship to neurological deficit, disability and depression. J Neurol. 2002; 249(9): 1160-1167. PMID:12242533. http://dx.doi.org/10.1007/s00415-002-0792-3

[10] Hopman WM, Verner J. Quality of life during and after inpatient stroke rehabilitation. Stroke. 2003; 34: 801-805. PMID:12624313. ht tp://dx.doi.org/10.1161/01.STR.0000057978.15397.6F

[11] Burton CR. Living with stroke: A phenomenological study. J Adv Nurs. 2000; 32: 301-309. PMID:10964176. http://dx.doi.org $/ 10.1046 / j .1365-2648.2000 .01477 . x$

[12] Nilsson I, Jansson L, Nordberg A. To meet with a stroke: Patients' experiences and aspects seen through a screen of crisis. J Adv Nurs. 1997; 25: 953-963. PMID:9147200. http://dx.doi.org/10.10 46/j.1365-2648.1997.1997025953.x

[13] Kirkevold M. The unfolding illness trajectory of stroke. Disabil Rehabil. 2002; 24: 887-898. PMID:12519484. http://dx.doi .org /10.1080/09638280210142239

[14] Eilertsen G, Kirkevold M, Bjork IT. Recovering from a stroke: a longitudinal, qualitative study of older Norwegian women. J Clin
Nurs. 2010; 19: 2004-2013. PMID:20920026. http://dx.doi.o $\mathrm{rg} / 10.1111 / \mathrm{j} .1365-2702.2009 .03138 . \mathrm{x}$

[15] Smith JA, Flowers P, Larkin M. Interpretative Phenomenological Analysis: Theory Method and Research. London: SAGE Publications; 2009.

[16] Heider F. The psychology of interpersonal relations. New York: Wiley and Sons; 1958. http://dx. doi.org/10.1037/10628-000

[17] Larkin M, Watts S, Clifton E. Giving voice and making sense in interpretative phenomenological analysis. Qualitative Research in Psychology. 2006; 3: 102-120. http://dx.doi.org/10.1191/1 478088706qp062oa

[18] Popovich JM, Fox PG, Bandagi R. Coping with stroke: Psychological and social dimensions in US patients. Int J Psychiatr Nurs Res. 2007; 12(3): 1474-1487. PMID:17682588.

[19] Banja JD. Stroke rehabilitation and the phenomenological reconstitution of the self. Top Stroke Rehabil. 2011; 18(1): 24-29. PMID:21371976. http://dx.doi.org/10.1310/tsr1801-24

[20] Bright FAS, Kayes NM, McCann CM, et al. Understanding hope after a stroke: a systematic review of the literature and concept analysis. Top Stroke Rehabil. 2011; 18(5): 490-508. PMID:22082700. http://dx.doi.org/10.1310/tsr1805-490

[21] Shinebourne P, Smith JA. The communicative power of metaphors: an analysis and interpretation of metaphors in accounts of the experience of addiction. Psychology and Psychotherapy: Theory, Research and Practice. 2010; 83(1): 59-73.

[22] Reid K, Flowers P, Larkin M. Exploring the lived experience. The Psychologist. 2005; 18(1): 20-23.

[23] Reiners GM. Understanding the differences between Husserl's (descriptive) and Heidegger's (interpretive) phenomenological research J Nurs Care. 2012; 1(5): 1000119. http://dx.doi .org/10.4172 /2167-1168.1000119

[24] Taylor C, Richardson A, Cowley S. Restoring embodied control following surgical treatment for colorectal cancer: a longitudinal qualitative study. Int J Nurs Stud. 2010; 47: 946-956. PMID:20096839. http://dx.doi.org/10.1016/j.ijnurstu.2009.12.008

[25] Murray CD, Harrsion D. The meaning and experiences of being a stroke survivor: An interpretative phenomenological analysis. Disabil Rehabil. 2004; 26(31): 808-16.

[26] Taylor SE. Adjustment to threatening events. A theory of cognitive adaptation. American Psychologist. 1983; 38(11): 1161-1173. http://dx.doi.org/10.1037/0003-066X.38.11.1161

[27] Hoth KF, Womboldt FS, Bowler R, et al. Attributions about cause of illness in chronic obstructive pulmonary disease. J Psychosom Res. 2011; 70: 465-472. PMID:21511077. http://dx.doi .org/10.10 16/j.jpsychores.2010.10.005

[28] Runions S, Arnaert A, Sourial R. Causal attributions and health behavior choices among stroke and transient ischemic attack survivors. J Neurosci Nurs. 2006; 38(4): 288-295. PMID:16989297. http://dx.doi.org/10.1097/01376517-200609000-00004 
[29] Roesch SC, Weiner B. A meta-analysis review of coping with illness. Do causal attributions matter? J Psychosom Res. 2001; 50: 205-219. http://dx.doi .org/10.1016/S0022-3999(01) 00188-X

[30] Festinger L. A theory of social comparison processes. Human Relations 7. 1954; 117-140. http://dx.doi.org/10.1177/0018726 75400700202

[31] Wills TA. Downward comparison principles in social psychology. Psychol Bull. 1981; 90: 245-271. http://dx.doi.org/10.1037 /0033-2909.90.2.245

[32] Buunk BP, Gibbons FX. Health, coping and well-being. Perspectives from social comparison theory. Erlbaum: Mahwah, NJ; 1997.

[33] Corcoran K, Cursius J, Mussweiler T. Social comparisons: motives, standards and mechanisms. In Theories in social psychology. Chadee D ed. Oxford: Wiley-Blackwell; 2011. 119-139p.

[34] Taylor SE, Lobe M. Social comparison activity under threat: downward evaluation and upward contacts. Psychological Review. 1989; 96: 569-575. PMID:2678204. http://dx.doi.org/10.1037/0 033-295X.96.4.569

[35] Arigo D, Suls JM, Smyth JM. Social comparisons and chronic illness: research synthesis and cultural implications. Health Psychol Rev. 2012; 1-61.

[36] World Health Organisation. Primary Health Care, Ama Ata. Geneva: World Health Organisation; 1978.

[37] Thompson AGH. The meaning of patient involvement and participation in healthcare consultations: A taxonomy. Soc Sci Med. 2007 64(6): 1297-1310. PMID:17174016. http://dx.doi.org/10.10 16/j.socscimed.2006.11.002
[38] Tutton E, Seers K, Langstaff D. Hope in orthopaedic trauma: a qualitative study. Int J Nur Stud. 2012; 49: 872-879.

[39] Cross A, Schneider M. A preliminary qualitative analysis of the impact of hope on stroke recovery in women. Top Stroke Rehabil. 2010; 17(6): 484-495. PMID:21239372. http://dx.doi.org/10.1310 /tsr1706-484

[40] Arnaert AA, Filteau NN, Sourial RR. Stroke patients in the acute phase: role of hope and self-healing. Holist Nurs Pract. 2006; 20(3): 137-146. PMID:16672814. http://dx.doi.org/10.1097/000 04650-200605000-00008

[41] Nygren B, Aléxa L, Jonséna E, et al. Resilience, sense of coherence, purpose in life and self-transcendence in relation to perceived physical and mental health among the oldest old. Aging and Mental Health. 2005; 9(4): 354-362. PMID:16019292. http: //dx.doi.org/10.1080/1360500114415

[42] Hildon Z, Smith G, Blane D, et al. Understanding adversity and resilience at older ages. Sociology of Health and Illness. 2008; 30(5): 726-40. PMID:18444953. http://dx.doi.org/10.1111/j.146 7-9566.2008.01087.x

[43] Glymour MM, Weuve J, Fay ME, et al. Social Ties and Cognitive Recovery after Stroke: Does Social Integration Promote Cognitive Resilience? Neuroepidemiology. 2008; 31(1): 10-20. PMID:18535395. http://dx.doi.org/10.1159/000136646

[44] Kinderman P, Bentall RP. A new measure of causal locus: the internal, personal and situational attributions questionnaire. Personality and Individual Differences. 1996; 20(2): 261-261. http: //dx.doi .org/10.1016/0191-8869 (95) 00186-7 